\title{
Ethical principles and recommendations for the medical management of differences of sex development (DSD)/intersex in children and adolescents
}

\author{
Claudia Wiesemann • Susanne Ude-Koeller • \\ Gernot H. G. Sinnecker • Ute Thyen
}

Received: 8 March 2009 / Accepted: 9 September 2009/Published online: 20 October 2009

(C) The Author(s) 2009. This article is published with open access at Springerlink.com

\begin{abstract}
The medical management of differences of sex development (DSD)/intersex in early childhood has been criticized by patients' advocates as well as bioethicists from an ethical point of view. Some call for a moratorium of any feminizing or masculinizing operations before the age of consent except for medical emergencies. No exhaustive ethical guidelines have been published until now. In particular, the role of the parents as legal representatives of the child is controversial. In the article, we develop, discuss, and present ethical principles and recommendations for the medical management of intersex/DSD in children and adolescents. We specify three basic ethical principles that have to be respected and substantiate them. The article includes a critical discussion of the best interest of the child and of family privacy. The argumentation draws upon recommendations by
\end{abstract}

C. Wiesemann $(\bowtie) \cdot$ S. Ude-Koeller

Department for Medical Ethics and History of Medicine,

Göttingen University,

Humboldtallee 36,

37073 Göttingen, Germany

e-mail: cwiesem@gwdg.de

URL: www.egm.med.uni-goettingen.de

S. Ude-Koeller

e-mail: sude@gwdg.de

G. H. G. Sinnecker

Klinikum der Stadt Wolfsburg,

Klinik für Kinder- und Jugendmedizin,

Sauerbruchstr. 7,

38440 Wolfsburg, Germany

e-mail: sinnecker@klinikum.wolfsburg.de

U. Thyen

Klinik für Kinder- und Jugendmedizin,

Universitätsklinikum Schleswig-Holstein,

Campus Lübeck Ratzeburger Allee 160,

23538 Lübeck, Germany

e-mail: thyen@paedia.ukl.mu-luebeck.de the working group "Bioethics and Intersex" within the German Network DSD/Intersex, which are presented in detail. Unlike other recommendations with regard to intersex, these guidelines represent a comprehensive view of the perspectives of clinicians, patients, and their families.

Conclusion The working group identified three leading ethical principles that apply to DSD management: (1) to foster the well-being of the child and the future adult, (2) to uphold the rights of children and adolescents to participate in and/or self-determine decisions that affect them now or later, and (3) to respect the family and parent-child relationships. Nine recommendations for the management of DSD indicate how these ethical principles can spelled out and balanced against each other in the clinical setting.

Keywords Intersex · Disorders of sex development · Ethics · Informed consent $\cdot$ Guidelines

Differences of sex development (DSD) ${ }^{1}$ - or intersex as it is sometimes called-has recently attracted considerable

\footnotetext{
$\overline{1}$ The term DSD meaning disorders of sex development was coined by the International Consensus Conference (2006). The notion "disorders," however, is criticized for its pathologizing tendency. In this paper, we use the terms "differences in sex development" or "intersex" to avoid a biased opinion. The field of intersex shows a wide range of variations from the statistically normal. We understand that in Western societies, there is a ongoing debate on which variations of sex development should be classified as male or female, normal or not normal, in need of a medical intervention or not, disorder or difference. This debate is unlikely to come to an end soon. For example, homosexuality was treated as a biological and psychological abnormality of sexual development, but is no longer today. Normality in medicine is a biological as well as a social criterion, and its meaning is changing over time. The notion "disease" or "disorder" implies that something is a relevant abnormality and that medicine is in charge of it. We want to avoid this reflex. However, we do not deny that there may be conditions requiring medical intervention.
} 
attention by pediatricians, endocrinologists, psychologists, and geneticists, as well as feminists, ethicists, and self-help groups [1-6]. A number of articles have been published to clarify the role medicine should play in shaping sex and gender identity in children with DSD. The new literature indicates a shift of the paradigm of a so-called "optimalgender policy," a term coined by the early pioneering group in the field from Johns Hopkins University in the 1960s. At the time, early corrective surgery was thought to help the affected children as well as their parents to facilitate stable gender identity and appropriate gender role behavior [7-9]. Sex assignment of infants with ambiguous genitalia often resulted in feminizing operations in moderate or severe undervirilization in 46,XY DSD as well as $46, \mathrm{XX}$ conditions with severe masculinization. Those critical of early surgery aiming at normal or near normal appearance argue that the complexity of gender identity was not considered adequately, and the mutilating and traumatizing effects of treatment were not sufficiently taken into account. Other than in the case of medical emergencies, they now advocate a moratorium in any feminizing or masculinizing operations before full consent may be obtained from the child $[10,11]$. This strategy can be called "full-consent policy."

Today, guidelines from medical societies still endorse techniques like clitoris reduction or vagina surgery in the newborn or infant, albeit more cautiously than before [12, 13]. However, the underlying ethical principles of DSD management have not been seriously scrutinized since Kenneth Kipnis and Milton Diamond's harsh criticism in the Journal of Clinical Ethics of the "optimal-gender policy," particularly for the deficiencies in informed decision making [11]. In 2004, an ad hoc group at the Hastings Center for Bioethics comprising clinicians, philosophers, and bioethicists, called for a multidisciplinary approach to the management of DSD, the child's right to know and rigorous follow-up studies but avoided tackling the contentious issue of decision making in early childhood [14]. A Consensus Statement on Management of Intersex Disorders issued by the participants of an International Consensus Conference in 2006 involving pediatric specialists from the United States, Great Britain, and Germany endorsed open communication, a reflective stance on gender identity and a focus on quality of life issuesencompassing "falling in love, dating, attraction, ability to develop intimate relationship, sexual functioning, and the opportunity to marry and raise children"-rather than the biological indicators of sex [15]. This statement offers a thorough appraisal of clinical procedures and psychosocial requirements but fails to give sound ethical arguments for the proposed strategies.

The aim of this paper is to identify and critically discuss those ethical principles that should be respected in medical decision making. Our argumentation draws upon the recommendations by the working group "Bioethics and Intersex" within the German Network DSD/Intersex, which are presented and developed in detail. We will delineate how the rights of the child and the future adult can best be defended by exploring the meaning of patient autonomy. We will also show why a moratorium on nonemergency intersex surgery in early childhood is not justified from an ethical point of view, and why family privacy has to be taken into account.

\section{Working group "bioethics and intersex" within the German Network DSD/Intersex}

Since 2004, a research network on DSD/intersex has been in operation in Germany, funded by the German Ministry of Education and Research within the research program for rare diseases. As part of the network, a working group "Bioethics and Intersex" was established to discuss guiding ethical principles and develop ethical guidelines for the clinical management of children with ambiguous genitalia.

The working group adopted a catalog of "Ethical principles and recommendations for the therapeutic management of differences of sex development (DSD)/Intersexuality in children and adolescents" outlined below. The working group consisted of members of patient support groups (persons with DSD/intersex and/or parents); bioethicists; specialists in pediatrics and adolescent medicine, surgery, urology, obstetrics and gynecology, endocrinology; a psychologist and psychotherapist; a specialist in medical law; and a medical sociologist. In a series of meetings, they familiarized themselves with the ethical, legal, psychosocial, and medical aspects concerning this subject and communicated with numerous experts in the field. The working group critically reviewed the diagnostic and therapeutic options available for individuals with ambiguous genitalia in the light of common bioethical principles. We have

- analyzed the concepts of health, disease, and quality of life with respect to interventions in persons with discordant chromosomal, gonadal, and anatomical sex, but without any acute health risks;

- delineated the fundamental conflicts and ethical principles which should guide any medical and surgical interventions;

- established the rights of children and the rights and duties of the parents and health-care teams with regard to these issues and developed a standard for decision making (based on informed consent).

A draft of the ethical principles and recommendations designed for the health-care team has been submitted to all members of the network for feedback and discussion. 


\section{Why are the ethical principles of DSD management contentious?}

The ethics work group identified four scientific and social tendencies as the major driving forces that led to a thorough reappraisal of former treatment regimes in DSD: (1) increasing knowledge about sex determination and differentiation and the complicated interaction of genotype and phenotype; (2) modern society's decreasing rigidity about the nature of sexual identity and gender roles following the women's liberation movement; (3) a growing unease about paternalism in medicine along with the advocacy of patients' and children's rights; and (4) the growing importance of patient support groups in the assessment of medical interventions. These factors have helped to re-evaluate the rationality of the "optimal-gender policy," once recommended by John Money and others. This strategy aimed at benefiting the child as well as the family by creating social certainty through surgical interventions "normalizing" the appearance of the external genitalia. At the time, the impact of hormones on the brain and other organs was underestimated, and the social impact of the stigma of being different was believed to create great distress for individuals affected by DSD. The concept has meanwhile fallen short of expectations. Its major shortcomings included: it was based on less than satisfactory scientific evidence of the long-term outcomes; it privileged phenotypic normalcy over bodily integrity and - to some extent also - quality of life; it systematically neglected the trauma inflicted on the child by medical interventions; and it often meant that neither the child and the future adult nor the parents were educated about the nature of the disorder and the purpose and extent of medical interventions. The last aspect-the secrecy within families and lack of informed consent even in adolescents-is in fact now considered the most problematic issue, as it immunized physicians' and parents' convictions from being falsified.

Meanwhile, intersex activists and the medical community itself have demanded for more evidence on the longterm outcome with regard not just to appearance but also to sexual satisfaction, reproductive functions, gender identity, and quality of life. As these data can only be provided when the patients and their families are fully informed about their condition, optimal gender policy has lost its attractiveness as a comprehensive and successful strategy for managing DSD.

\section{Patient autonomy and postponed informed consent}

Some critics believe that informed consent by patients is the only way to legitimate appearance-normalizing surgery in
DSD. Given the importance of this ethical concept in modern medicine, this is no surprise [15]. Without the competent patient's informed consent, a medical intervention amounts to battery [16]. Critics of early surgical interventions have cast doubt on parental surrogate decision making. Parents' surrogacy, they argue, should extend merely to decisions that are in the objective best interest of the child [17, 18]. The appearance of the external genitalia in DSD generally causes no medical problems or immediate health threats to the child. Moreover, most surgical interventions are irreversible and may restrict later options for sex reversal. As it is difficult to find out what is in the best interest of the child, nobody, the argument goes, should decide on these important questions except the patient $\mathrm{him} /$ herself. This position entails postponing minor interventions at least until the age of 5 or 6 , when the child is able to express preferences and major interventions until the age of 12 to 14 .

Although appealing in its simplicity, the argument, however, is flawed: it does not sufficiently distinguish between the interests of the child, particularly the small one, and those of the future adult. That which benefits the child at the age of 3 or 4 and the teenager or adult at 15 or 20 , might not be identical at all. Whereas the small child might depend upon a stable gender identity role and undisturbed relations to his or her peers and prefer conformity over independence, the young grown-up might cherish authenticity, independence, and the right freely to choose relationships that suit him or her well. According to the maxim of postponed informed consent, only the adult would be truly able to determine the best interests of the child he or she was in a former time. But this child no longer exists, and its interests, thus, can no longer be respected.

For example, a child with incomplete Androgen Insensitivity Syndrome raised as a girl might in puberty face the effects of virilizing hormones. Hormone suppression has to start before puberty to avoid the effects of male-typical pubertal development and to prevent major disturbances in gender identity. Postponing this decision to the age of consent, however, means closing an important window of opportunity for the child. The future adult's consent, thus, will be meaningless, because no decision will undo the consequences of a waiver of treatment in the past. Like "optimal-gender policy," the strategy of postponed consent also has a self-immunizing tendency, as it implicitly treats the small child's wishes as irrelevant. Demanding a surgical moratorium until the age of consent had been an understandable reaction to nonjustified surgical optimism in the past, but nevertheless resembles the strategy in an old joke: A man has lost his keys in the dark, but is looking for them under a street lamp since he would otherwise not be able to find them. 


\section{Family privacy and the best interest of the child}

A sound ethical justification for treatment decisions in early childhood is indeed the key to decision making in DSD. The right to represent the child and to decide on its behalf is normally accorded to the parents as legal guardians. However, their role in DSD management is contested. Dayner et al., e.g., showed that parents of 46,XX children with congenital adrenal hyperplasia mostly are in favor of early genital clitoris reduction, even at the risk of reducing genital sensitivity, although it is not clear that this is in the interest of the child [19]. Patient support groups argue that "in intersex conditions the parents' wishes often conflict with the child's ultimate best interest" $[20,21]$.

The double superlative "ultimate best," however, hints to some characteristic difficulties associated with the so-called best interest standard in pediatric ethics that might step in, in the place of informed consent. Ethicists agree upon the fact that the lower threshold of what is definitely not in the interest of the child can be fixed, such as anything that is purposefully destructive or even life-threatening. They would also agree on what counts as an ethical minimum of parental care, such as adequate clothing, nourishment, and education $[22,23]$. However, this is far from establishing an objective ethical maximum as is implied by the notion "best" (let alone "ultimate best") in best interest standard. In modern pluralistic societies, there is no such criterion as an objective best interest standard for child care. Although quite commonly used in ethical debate, this notion is misleading and should be abandoned because it suggests an objective external value system with a linear scale, which does not exist, for optimal parental behavior $[24,25]$. Parents and families are instead accorded a certain sphere of privacy to pursue their personal aims and find out what is their best in child care [26]. The Universal Declaration of Human Rights, for example, acknowledges this fact when stating: "The family is the natural and fundamental group unit of society and is entitled to protection by society and the State" [27]. Protection for the child means not just protection by but also protection from society and the state. The same attitude is expressed by the UN Convention of the Rights of the Child. The signing states are "convinced that the family, as the fundamental group of society and the natural environment for the growth and well-being of all its members and particularly children, should be afforded the necessary protection and assistance so that it can fully assume its responsibilities within the community" [28].

Thus, parents take first-line responsibility in defining what might be best for the child, and this may rightly vary according to their individual experience and life style, cultural expectations, and beliefs. The right to familial privacy, however, is not unlimited. It has to comply with the ethos of parenthood determined by the larger cultural context, not just by the individual parents themselves. This almost universal ethos demands both a caring and encouraging human relationship between parent and child and respect for each and every child [29]. The way in which parents are expected to live up to this ethos has to be socially negotiated in line with social, cultural, or religious attitudes.

The nature and extent of restrictions the state may impose upon the family to protect children from harm and to help parents realize the ethos of parenthood is an ongoing controversy in modern societies. The debate on in vitro fertilization for gay couples is one example; the limits of parental discretion and decision making about a child's sex and gender identity is another.

Given the importance of supportive personal relationships for children in general and the difficulties in objectively and externally defining the child's best interest, parents should play a major role in the decision-making process in DSD management. Given the complexity of interaction between biological, psychological, social, and cultural factors, it is also essential to make decisions on a case-by-case basis. This forecloses such sweeping recommendations for each and every case like a general moratorium on surgical interventions in DSD in early childhood, as well as simple formulas for the treatment of particular disease conditions. Biological, psychological, and social factors have an influence on the outcome of a case and make each intersex condition unique. The individual characteristics of the child, the family, and the social background have a bearing on the benefits to be achieved for the child and thus, have to be taken into account.

Nevertheless, it is necessary to outline some general principles limiting parental discretion in accordance with commonly shared beliefs of the good parent on one hand and of the child's human dignity and bodily integrity on the other hand. First of all, the child itself is to be respected as another major player in the decision-making process. Even the small child can express preferences or vetoes. As early as the age of 6 or 7 , children are able to understand biological processes or to reflect on their identity [30]. The child, therefore, should be granted partnership status and be involved in all examination and treatment steps, as appropriate to his or her developmental level. This helps to modify the family perspective usually represented by the parents.

Secondly, all persons involved should be aware of the fact that a good parent-child relationship is the result of a process of continuing efforts and not just a state of mind. It can be facilitated by appropriate therapeutic interventions. Due to the psychosocial stress associated with DSD, parents need help in establishing a good relationship with their child. Psychological support should always be sought 
to help families to strive for a good relationship with the child and to support the child in developing supportive relationships in the peer group. If the family's right to decision making is endorsed, the relationships within the family deserve careful consideration and have to be included in the therapeutic process. Thirdly, the outcome - as judged by minor and adult intersex patients - of any intervention should be continuously and carefully evaluated and inform future treatment recommendations.

\section{Conclusions}

The working group identified three ethical principles relevant to decision making in DSD. First of all, the wellbeing of the child and of the future adult has to be fostered. It is important to note that the surgical creation of unambiguous external genitalia is neither necessary nor sufficient criterion for well-being and is sometimes impossible to achieve; bodily integrity and quality of life, particularly with respect to reproductive capability as well as the ability to experience sex, and the free development of the child's personality have also to be taken into account. Secondly, the rights of the patients to participate in and/or self-determine decisions that affect them now or later have to be respected. This includes the right of the future adult to be comprehensively informed about their condition and about all interventions carried out as well as the health-care team's obligation to provide the appropriate information and maintain documentation. Thirdly, family and parentchild relationships should be fostered. Parents have the right to represent their child in the decision-making process, particularly when there is no clear evidence of the outcome of medical interventions and when the interest of the small child and the future adult might not be identical. The healthcare team has to strengthen the ability of parents to cope with the situation and to support their child. For that purpose, parents have to receive professional support and assistance.

The Ethics Work Group was aware of the fact that these three principles often conflict. Nine recommendations for the management of DSD published below indicate how they can be balanced against each other in the clinical setting.

Decision making concerning sex assignment and consequent surgical interventions are hampered by the lack of evidence in many conditions causing ambiguous genitalia in newborns or children during their development. All decisions must be based on the individual's unique condition and prognosis from a biological and social perspective. Thus, we foster a shift in paradigm from optimal appearance and potential functioning to optimal emotional and social development trying to maximize the child's and future adults' participation in decision making on one hand and a good parent-child relationship on the other.
Acknowledgment This research project was part of the German Research Network Intersex (U. Thyen/O.Hiort) funded by the German Ministry of Education and Research. The authors thank Deborah Landry for translating the Addendum.

Conflict of interest The authors declare that they have no conflict of interest.

Open Access This article is distributed under the terms of the Creative Commons Attribution Noncommercial License which permits any noncommercial use, distribution, and reproduction in any medium, provided the original author(s) and source are credited.

\section{Addendum}

\section{Ethical Principles and Recommendations for the Medical Management of Differences of Sex Development (DSD)/Intersex in Children and Adolescents}

\author{
Ethics Work Group ${ }^{2}$ in the Intersex Network "Differences \\ of Sex Development" ${ }^{\prime 3}$
}

Introduction In medicine, "differences of sex development" (DSD) or "intersex" are defined as a congenital mismatch between chromosomes and the internal and external genitalia in one person. From a biological perspective, such conditions involve various manifestations of an incomplete development of sex anatomy (e.g., vaginal or gonadal agenesis) and/or of disturbances in the production or action of sex hormones. In persons with complex hormone disorders, other body systems may also be affected.

The principles and recommendations outlined herein address the ethical aspects of medical interventions for correcting atypical internal or external genitalia, whereas they do not discuss the diseases and conditions that can develop as sequelae of DSD. Conflicts tend to arise due to the lack of a social environment in which children with DSD can experience their "otherness" as normal.

\footnotetext{
${ }^{2}$ Members of the Working Group: Prof. Claudia Wiesemann, M.D. (Medical Ethics/Working Group leader), Andrea Dörries, M.D. (Medical Ethics/Pediatric and Adolescent Medicine), Eva Hampel, Ph.D. (Medical Sociology), Gerda Janssen-Schmidchen (member of a parent's group), Eckhard Korsch, M.D. (Pediatric Endocrinology, Pediatric and Adolescent Medicine), Eveline Kraus-Kinsky (self-help group member), Clothilde Leriche, M.D. (Pediatric Surgery), Eveline Loeser, M.D. (Obstetrics and Gynecology, Pediatric and Adolescent Gynecology), Luise Müller (Working Group coordinator), Heiko Reutter, M.D. (self-help group member), Sonja Rothärmel, J.D. (Medical Law), Prof. Gernot H.G. Sinnecker, M.D. (Pediatric Endocrinology, Pediatric and Adolescent Medicine), Susanne Ude-Koeller, Ph.D. (Medical Ethics), Knut Werner-Rosen (Psychology/Psychotherapy), Prof. Gerhard Zöller, M.D. (Urology), and one additional self-help group member.

${ }^{3}$ Funded by the German Ministry of Education and Research
} 
When a child is born with ambiguous internal or external genitalia, the affected persons, their families, and the attending medical team are put in a difficult situation. Such constellations are often identified within the first days of the child's birth. At this early stage, decisions have to be made as to how to proceed without knowing what the orientation, interests, or needs of the future adolescent and adult will be. Irrespective of whether a choice is made in favor of or against treatment, the path taken is virtually always irreversible while, at the same time, interfering in highly sensitive domains, affecting reproduction, sexuality, physical and mental integrity, and the formation of a person's self-identity as well as the parent-child relationship. Faced with these issues, most parents feel overwhelmed by the magnitude of the decision they have to make on behalf of their child. Moreover, considering the consequences of any medical interventions taken or not, the attending team is equally confronted with a dilemma, not least when initiating measures and interventions that are not substantiated by valid evidence from any long-term studies. In spite of this, when it comes to deciding on treatment, medical expertise is frequently given the decisive edge.

In both medical circles and among affected individuals, it remains controversial whether these conditions, and if so, which of them should be regarded as abnormal and as requiring treatment. Gender identity is determined by biological, psychological, and social factors. An assignment to one gender, based solely on biological or morphological criteria, does justice neither to the person's individuality and subjectivity nor to the fact that gender identity is dependent upon social and psychological factors. Affected persons and self-help organizations regard the term "intersex" as overly narrow, stigmatizing, and discriminatory on one hand, but also as a stimulus to identity formation on the other. The term intersex is, thus, just as ambivalent as the deviation from the sexual norm from which the word derives its meaning.

Sexual ambiguity is not a condition requiring treatment per se. Affected persons are not the only ones who fundamentally question medicine's mission to heal patients with DSD. They experience the societal pressure for sexual differentiation into male and female and/or for sexual unambiguousness as pathologizing. Two different concepts of gender identity have been proposed to explain gender deviation from the norm. Proponents of the biological-scientific model emphasize the consequences of prenatal genetic and hormonal influences on sex differentiation and thus, on gender. By contrast, advocates of the social constructivist model argue that gender differentiation follows from social norms.

Starting position of the authors for these principles and recommendations The authors of these principles and recommendations understand the two models to be com- plementary. Hence, the following communication on DSD will address aspects of both concepts. They do not wish to assign a fundamentally pathological meaning to DSD. The concept reflects society's norms regarding gender identity, which are currently undergoing a historical transformation. The authors are fully aware of the problems associated with these issues, respect the disconcertment and the rejection caused by foreign assignation of gender roles, and accept that alternative concepts exist among individuals.

The authors of the principles and recommendations are aware of the fact that the medical concept of DSD reflects societal problems that may no longer arise with such acuity in the future, as gender roles change. Notwithstanding the above, it is necessary to develop options for how to act in light of the present situation and to help today's actors make decisions and cope with conflicts.

The aims of these principles and recommendations These recommendations are intended for medical professionals as well as for all other persons involved with the diagnosis, treatment, care, and psychosocial support of children and adolescents with DSD. This includes persons in the following specialties: obstetrics and midwifery, pediatric and adolescent medicine, (pediatric) endocrinology, (pediatric) surgery, (pediatric) urology, (pediatric and adolescent) gynecology, (pediatric and adolescent) psychotherapy, and (pediatric) nursing. The goal is to employ a sensitive and patient-centered management once an "ambiguous sex" has been established and to ensure that the affected persons achieve the highest possible degree of present and future quality of life. For this, it is imperative that the multidisciplinary health-care team work in close cooperation with the affected children and adolescents, their parents, and self-help organizations. Still, the principles and recommendations shall neither relieve the parents, as the children's guardians, nor the members of the multidisciplinary healthcare team from personal responsibility for their own behavior and decision making as appropriate to each individual case.

Guiding ethical principles These principles and recommendations are built upon respect for the patient's selfdetermination and upon the participatory rights of children. They give due consideration to the well-being of the child (including of the child's right to a good parent-child relationship) and regard the parents not only as the representatives of their children in all treatment decisions, but also as affected persons who themselves require help and support. They take into account the fact that the process of cultural transformation within society is characterized by a gradual breaking of gender norms as well as a greater tolerance for gender ambiguity in men and women. Knowing the extent to which taboos were previously 
associated with this subject and that affected persons still suffer stigmatization, the authors of these principles and recommendations aim to promote professionalism, respect, and tolerance in the management of DSD and to counteract any stigmatizing behavior by the medical community and society.

Upholding different ethical principles such as beneficence, nonmaleficence, and patient autonomy can lead to contradictory conclusions concerning imminent treatment decisions. The treatment of children and adolescents with differences of sex development is associated with bioethical problems that derive from the prognostic uncertainty, the time span of the prognosis, and the insufficiency of available evidence interrelated with these factors; indeed, the question of what exactly is in the best interest of the child and of the respectively future adult can frequently not be decided with certainty. Decisions made by parents as the guardians of children not yet capable of giving consent must be carefully weighed, given the breadth and scope of the therapeutic decisions to be made. At the same time, it must be kept in mind that the interests of the future adultsalthough an important gauge for the clinical decision making - are not automatically in concordance with the interests of the child. For children, especially for small children, a loving and trusting relationship with its parents is of immense importance. Thus, caring for the parents and fostering a good parent-child relationship is incumbent upon all members of the multidisciplinary health-care team. Their aim should be enabling the parents to deal with their child in a responsible, loving, and relaxed manner.

Three ethical principles and/or rights can be delineated here:

- foster the well-being of the child and the future adult. This includes their bodily integrity and quality of life, particularly with respect to reproductive capability as well as ability to experience sex, and the free development of their personality.

- uphold the rights of children and adolescents to participate in and/or self-determine decisions that affect them now or later. This includes the right of the future adult to be comprehensively informed about their condition and about all interventions carried out as well as the multidisciplinary health-care team's obligation to provide the appropriate information and maintain documentation.

- respect the family and parent-child relationship. This includes the rights and the duties of the parents to represent their child in the decision-making process and their right to receive professional support and assistance from the multidisciplinary health-care team.

The aim shall be to achieve a balance between the rights, needs, and interests as delineated.
Principles and recommendations for the multidisciplinary health-care team

1. Differences of sex differentiation do not per se require correction and for newborns, do not represent a surgical emergency, but in general, a psychosocial one. Every therapeutic decision that is not aimed at averting imminent danger to the life and health of the child should be weighed carefully without undue time constraints, given due consideration to different options and be reviewed scrupulously in consultation between members of the multidisciplinary health-care team and the parents.

2. Right from the start, the multidisciplinary health-care team must comprehensively involve the parents in the decision-making and therapy-planning process and be convinced that the parents have understood the planned interventions, their significance, and scope. Legally, the parents have the ultimate right to decide.

3. The child's well-being is not automatically ensured by determining an external and/or biologically unambiguous sex. The development of the child's self-confidence and self-esteem regarding its personal and gender identity is a therapeutic objective of high priority. Indeed, this is firstly achieved by supporting and accepting the child and secondarily, at best by endowing the child with specific bodily parts. The authors of these principles and recommendations are aware that it is not always possible to delineate clearly between functionally meaningful interventions and those that serve purely esthetic corrective functions - for example in the case of a genitoplasty or vaginal reconstruction. Here, each case must be weighed on its own merits. Whenever there is doubt, the psychological and social support of the child and its parents is to be ranked higher than the creation of biological normalcy. Moreover, bringing up the child in one gender without surgical esthetic correction reserves for the child the option to change gender identity later if deemed necessary. When assessing the child's well-being, any possible uncertainty or trauma relating to surgical interventions, corrective measures, and repeated examinations of the genital area should be given as much consideration as potential limitations to their capacity to experience sex or to their reproductive capability as future adults. Such aspects must be weighed against the benefits to be gained for the child through an external or biologically unambiguous sexual identity, given the fact that the issue of surgical timing is contentious with regard to achieving the optimal surgical outcome.

4. A therapeutic stance of openness and acceptance is to be encouraged. This attitude has a long-lasting influence on the development of a good parent-child relationship - an additional key therapeutic objective. The family environment, the cultural context, and the 
preferred value system of the affected family must be given due consideration. Special efforts should be made to help parents cope with the associated conflicts. To this end, parents should also be supplied with information about self-help groups and similar organizations. In line with their needs and wishes, the appropriate contacts with the family should be liaised with, and/or the family should be encouraged to make such contacts.

5. All interventions must be based upon the most exhaustive diagnostics and the best possible prognosis including the child's and its family's overall situation. To do so, it is indispensable that specialists from multiple disciplines hold mutual consultations. The less evidence there is for a specific procedure, the more important it is to seek additional expert opinions about it. The team should always consist of competent representatives from the fields of medicine, nursing, psychology, and psychotherapy as well as social workers. Overcoming one's own feelings of shame and unease is part of an appropriate professional stance.

6. Explicit reasoning and justification are necessary when interventions are being considered that are not substantiated by any satisfactorily conclusive scientific evidence. A compelling medical indication is necessary for interventions that might have irreversible consequences for the person's sex or negative consequences on their sexuality or reproductive capability. Likewise, when interventions that might have such consequences are refrained from, explicit reasoning and justification are required to back this up. In general, whenever prognostically uncertain interventions can be delayed until the child is old enough to make decisions for themselves, this option should be presented to parents as the preference of choice. As a rule, unless the child's well-being would otherwise be severely impaired, decisions about the removal of organs or structures important to an individual's physical integrity or sexual identity (such as gonads) should be left up to the affected persons themselves. If at all, interventions that are not supported by sufficient evidence are best performed under study conditions and at specialized facilities.

7. The child should be given information about its condition that is commensurate with its age. Its participation in therapeutic decision making is an indispensable part of treatment. This right should be respected at the earliest possible stage. A child has veto rights even at a very young age, whenever an intervention is not urgent for the child's health and when it is plainly contrary to the child's own will. The older a child becomes, the more its opinion should be observed and respected alongside that of the parents. In general, once an adolescent reaches the age of 14, it has the right to sole consent to a curative procedure. It is imperative to ensure at all times that circumstances commensurate with the child's age are maintained during examinations and treatments and that consideration is given to the child's feeling of shame. Geared to its developmental level, the child should be given partnership status and involved in all examination and treatment steps accordingly.

8. The right of the future adult to obtain information about the treatment it received during childhood must be upheld through seamless documentation. Affected persons capable of self-determination and/or their parents should be told that they are entitled to inspect their medical records. It is in the child's interest to keep detailed records of findings and treatments which are important for full disclosure of medical interventions later in life. All record keeping should be done with due respect for the patient's personal dignity and need for privacy. Disclosure of findings to third parties for purposes that imply no direct benefit for the affected patient is only permissible after careful appraisal of the advantages and disadvantages and always requires the informed consent of the affected persons and/or of their guardians. Data protection regulations must be scrupulously observed during record keeping and archiving of personal data in research projects.

9. These principles and recommendations should be reviewed at regular intervals and adapted to the most recent scientific and medical findings. Accompanying ethical research should help evaluate whether they can be feasibly put into practice and to what extent the affected persons, their parents, or the health-care team find them to be helpful and appropriate.

\section{References}

1. Chase C (1998) Surgical progress is not the answer to intersexuality. J Clin Ethics 9:385-392

2. Diamond M, Beh HG (2008) Changes in management of children with intersex conditions. Nat Clin Pract Endocrinol Metab 4:4-5

3. Diamond M, Sigmundson HK (1997) Sex reassignment at birth. Long-term review and clinical implications. Arch Pediatr Adolesc Med 151:298-304

4. Dreger AD (1999) When medicine goes too far in the pursuit of normality. Health Ethics Today 10(1)

5. Thyen U, Richter-Appelt H, Wiesemann C, Holterhus P-M, Hiort $\mathrm{O}$ (2005) Deciding on gender in children with intersex conditions. Considerations and controversies. Treatments in Endocrinology $4: 1-8$

6. Zucker KJ (2002) Intersexuality and gender identity differentiation. J Pediatr Adolesc Gynecol 15:3-13

7. Diamond M (2004) Sex, gender, and identity over the years: a changing perspective. Child Adolesc Psychiatr Clin N Am 13:591-607 
8. Money J, Hampson JG, Hampson JL (1955) Hermaphroditism: recommendation concerning assignment of sex, change of sex psychologic management. Bulletin of the John Hopkins Hospital 97:284-300

9. Money J (1975) Ablatio penis: normal male infant sex-reassigned as a girl. Arch Sex Behav 4:65-71

10. Beh HG, Diamond M (2000) An emerging ethical and medical dilemma: should physicians perform sex assignment surgery on infants with ambiguous genitalia? Mich J Gend Law 7(1):1-63

11. Kipnis K, Diamond M (1998) Pediatric ethics and the surgical assignment of sex. J Clin Ethics 9:398-410

12. British Association of Paediatric Surgeons Working Party (2003) Surgical management of children born with ambiguous genitalia. Arch Dis Child 88:799-801

13. Deutsche Gesellschaft für Urologie (2008) Störungen der sexuellen Differenzierung. http://www.dggg.de/_download/unprotected/ g_01_07_05_stoerungen_sexuellen_differenzierung.pdf. Accessed 23 January 2009

14. Frader J, Alderson P, Asch A, Aspinall C, Davis D, Dreger AD, Edwards J, Feder EK, Frank A, Hedley LA, Kittay E, Marsh J, Miller PS, Mouradian W, Nelson H, Parens E (2004) Health care professionals and intersex conditions. Arch Pediatr Adolesc Med 158:426-428

15. Hughes IA, Houk SF, Ahmed SF, Lee PA, LWPES/ESPE Consensus Group (2006) Consensus statement on management of intersex disorders. Pediatrics 118:e488-e500

16. De Lourdes Levy M, Larcher V, Kurz R, Members of the Ethics Working Group of the CESP (2004) Informed consent/assent in children. Statement of the Ethics Working Group of the Confederation of European Specialists in Paediatrics. Eur J Pediatr 162:629633

17. Diamond M, Sigmundson HK (1997) Management of intersexuality. Guidelines for dealing with persons with ambiguous genitalia. Arch Pediatr Adolesc Med 151:1046-1050

18. Ford K-K (2001) "First, do no harm"- the fiction of legal parental consent to genital-normalizing surgery on intersexed infants. Yale Law Policy Rev 19:469-488
19. Dayner JE, Lee PA, Houk CP (2004) Medical treatment of intersex: parental perspectives. J Urol 172:1762-1765

20. Chase C (2003) What is the agenda of the intersex patient advocacy movement? Endocrinologist 13:240-242

21. Diamond M, Beh HG (2006) The right to be wrong. Sex and gender decisions. In: Systsma SE (ed) Ethics and intersex. Springer, Dordrecht, pp 103-113

22. Kopelman LM (2005) The best-interest standard as threshold, ideal, and standard of reasonableness. In: Freeman M (ed) Children, medicine, and the law. Freegate, Burlington, Vermont, pp 425-443

23. Ross LF (1998) Children, families, and health care decision making. Clarendon, Oxford

24. Parens E (2006) Surgically shaping children. Technology, ethics, and the pursuit of normality. The Johns Hopkins University Press, Baltimore

25. Wiesemann C, Ude-Koeller S (2008) Richtlinien für medizinische Interventionen bei Kindern und Jugendlichen mit besonderer Geschlechtsentwicklung (Intersexualität): Was nützt der bestinterest standard? In: Groß D, Neuschaefer-Rube C, Steinmetzer J (eds) Transsexualität und Intersexualität. Medizinische, ethische, soziale und juristische Aspekte, Medizinisch wissenschaftliche Verlagsgesellschaft, Berlin, pp. 13-21

26. Daaboul J, Frader J (2001) Ethics and the management of the patient with intersex: a middle way. J Pediatr Endocrinol Metab 14:1575-1583

27. United Nations (1948) Universal Declaration of Human Rights, Art. 16 (3). http://www.un.org/Overview/rights.html. Accessed 23 January 2009

28. United Nations (1989) UN Convention of the Rights of the Child, Preamble. http://www2.ohchr.org/english/law/crc.htm. Accessed 23 January 2009

29. Wiesemann C (2006) Von der Verantwortung, ein Kind zu bekommen. Eine Ethik der Elternschaft. C H Beck, München

30. Dorn LD, Susman EJ, Fletcher JC (1995) Informed consent in children and adolescents: age, maturation and psychological state. J Adolesc Health 16:185-190 